\title{
Subsurface Alluvial Stratigraphy for Artificial Recharge of Ground Water using Geoelectrical Technique around Southwestern Part of Varanasi District, U.P., India
}

\author{
G. S. Yadav', S. K. Singh ${ }^{2}$ \\ ${ }^{1}$ Department of Geophysics, Faculty of Science, Institute of Science, Banaras Hindu University, Varanasi -221005, U.P., India \\ ${ }^{2}$ Central Ground Water Board, Lucknow, U.P., India
}

\begin{abstract}
Eighty-four geoelectrical soundings (GS) were carried out with maximum current electrode spacing of $1200 \mathrm{~m}$ using Schlumberger array for the study of subsurface alluvial stratigraphy for ground water recharge around southwestern part of Varanasi District, U.P., India. The GS data were interpreted using partial curve matching and Automatic Iterative Method of Resistivity Sounding Interpretation (AIMRESI) techniques. Based on the geoelectrical parameters obtained through the interpretation of sounding data and lithological informations available through boreholes, five vertical geoelectrical cross-sections and seven horizontal geoelectrical crosssections (slicing) at a specific depth levels have been prepared which clearly show the picture of lithological variation in the subsurface. The entire area is comprised of older and newer alluvium with different grades of sand, silt and clay. The occurrence of ground water has been identified in the sandy formations. The surface condition of the area under study reveals that the artificial recharge can be done by various means to fulfill the future demands.
\end{abstract}

Keywords: Alluvial stratigraphy, Artificial recharge, Geoelectrical sounding, Geoelectrical cross-section, Ground water, Hydrogeology

\section{Introduction}

The area under investigation forms a part of the great alluvial tract of Indo-Gangetic plain, which separates the Peninsular India from the extra-peninsular region of the Himalayan ranges. In the near subsurface, ground water occurs under the unconfined condition and is mostly tapped by dug-wells in the alluvial area. The deeper aquifer occurs in fine to coarse grained sandy layers occurring at various depths in alluvium. These deeper aquifers are under semiconfined and confined conditions. In some parts of the area, surface water bodies like canals and tanks have been the main source of supplemental irrigation besides ground water resources. However, due to industrial development and agricultural growth there is maximum use of ground water compared to the surface water which created decline in ground water table/level. Analysis of remote sensing imagery for the study of soil types, wells, land use, cropping pattern in the area around southwestern region of Varanasi was carried out by Yadav (2005). Some studies on Ground Water potential in the area around the same region was carried out by Yadav (2008). Studies on evaluation of ground water resources using geoelectrical techniques in some parts of alluvial and hard rock areas of eastern Uttar Pradesh, India was presented by Singh (2010). Ground water resources in the area have been exploited mostly through shallow dug-wells, hand pumps, dug-cum-bore wells and tubewells. Due to this reason ground water level is declining continuously day by day for which necessary steps have to be taken up after studying the subsurface alluvial stratigraphy of the area.

\section{Geomorphology and Geology of the Study Area}

The area under investigation around Rajatalab, lies in the south-western part of Varanasi district (Latitude $25^{\circ} 14^{\prime} 00^{\prime \prime}$ $\mathrm{N}$ to $25^{\circ} 20^{\prime} 00^{\prime \prime} \mathrm{N}$ and $82^{\circ} 47^{\prime} 00^{\prime \prime} \mathrm{E}$ to $82^{\circ} 54^{\prime} 00^{\prime \prime} \mathrm{E}$ ) which covers an area of approximately 144 sq. $\mathrm{km}$ and partly falls in Survey of India toposheet (No. 63K/15 and 63K/16) at 1:50,000 scales (Fig. 1). The River Ganga and its main tributary Varuna flow near the study area in south-eastern side and northern side, respectively. The ground surface gently slopes towards south-east. The general elevation of the ground surface is about $79 \mathrm{~m}$ above the mean sea level.

A brief account of geology of Varanasi region has been given by Pascoe (1968), Wadia (1975), Pathak (1977), Mehrotra (1980) and Krishnan (1982). The latest phase of the geological history of Varanasi region commences with the formation of fore-deep, concurrent with the uplift of the Himalayan mountain system. The fore-deep developed as a down wrap in the front of the crust waves of the Himalayan range as a result of obstruction of these waves when they moved southwards by the stable land mass of peninsular India. The fore-deep gradually was filled up in a very complicated geological environment and its details are not fully known and still this is an enigma among the geologists/geophysicists and needs extensive study. Upto a depth of 120 meters, the sediment underlying around Varanasi area comprises of sand, silt, clay and clay with kankar (kankar is a local name for nodular concretion of calcium carbonate). Sands and clays are of alluvial origin and the formation of the kankar may be due to the precipitation of calcium carbonate from ground water. The 


\section{International Journal of Science and Research (IJSR) \\ ISSN (Online): 2319-7064 \\ Index Copernicus Value (2013): 6.14 | Impact Factor (2014): 5.611}

alluvial deposits show a thick sequence of sand deposition overlain by clay and at some places clay with Kankar. The thickness of the sand bed varies from 18 to 65 meters. However, the average thickness is 40 meter (Pathak, 1977).

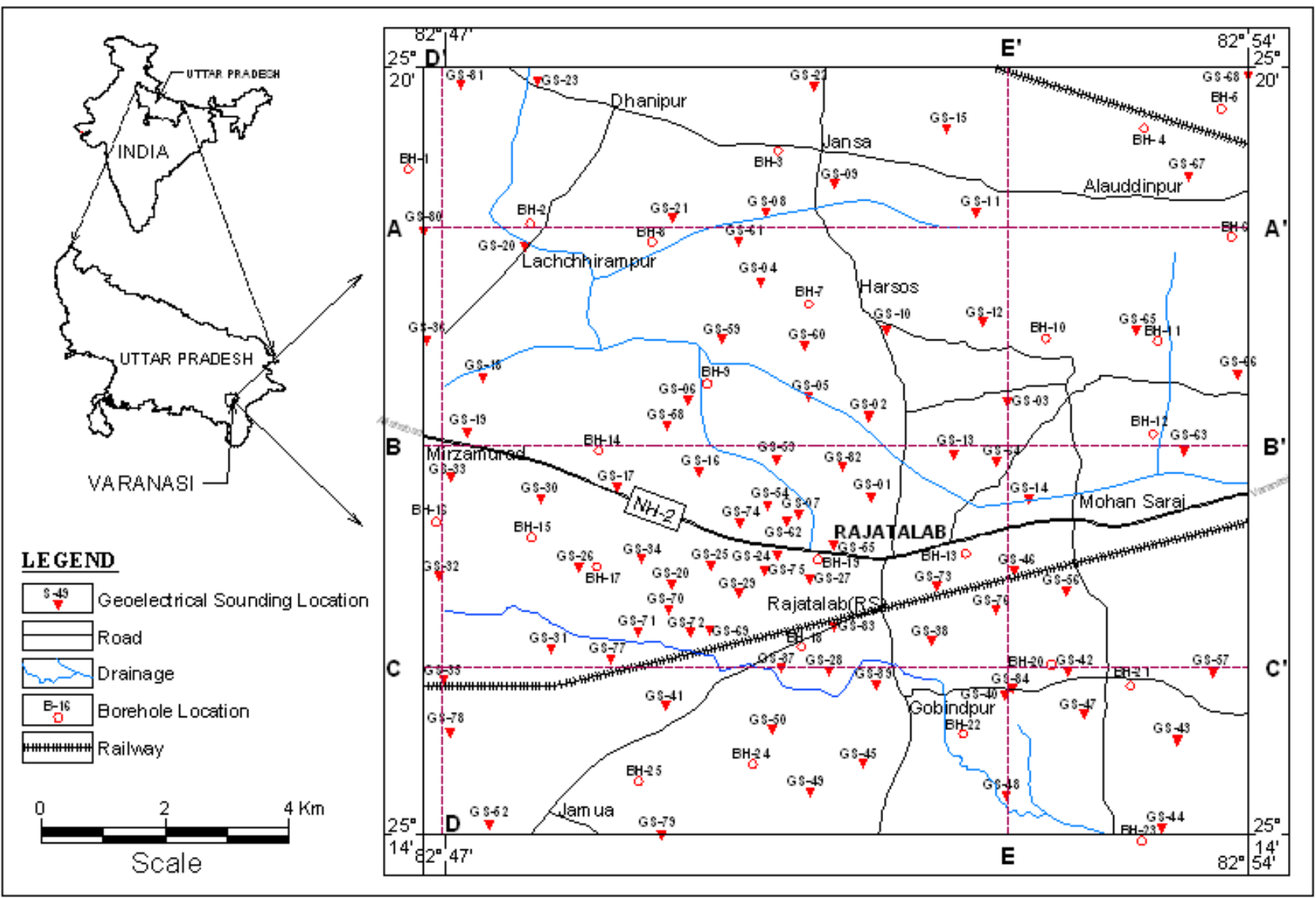

Figure 1: Location map of the study area

The lowering of sea level must have rejuvenated streams which brought about destruction of the terrain by channel sculpturing and scouring. During the interglacial period when the glacial ice melted, it carried with it vast quantities of rock debris which were deposited in the Ganga valley. The deposition cycle was completed with the flattening of the river gradient due to rise in the sea level resulting in back swamp and natural levee deposits of the Ganga and other tributaries. There are four glacial and three inter glacial periods exerted in the Himalaya and this cycle of erosion and disposition continued during these changing climates.

These deposits were also brought by the rivers from the Himalaya by erosion and are known as "Alluvium". The past geological records of the Indo-Gangetic plain lie beneath the thick mantle of alluvium, the geology of this region is, thus, completely unknown (Wadia, 1975). As mentioned earlier, the alluvial deposits of the Indo-Gangetic plain have been derived from the Himalaya ranges by the numerous rivers emerging from them during a period of the great gradational activity. The continuous up-heaving of mountains must have rejuvenated the streams again and again thus multiplying their eroding and transporting capacities.

\section{Method of Investigations}

Eighty-four Geoelectrical Soundings (GS) were conducted with maximum current electrode spacing of $1200 \mathrm{~m}$ at suitable location in the study area using the Schlumberger configuration. In the present study, a two step process was used to present the quantitative analysis and interpretation of GS field curves. In the first step, partial curve matching technique using auxiliary point charts of Ebert (1943) and master curves of Rijkswaterstaat (1969) was utilized which obtains the approximate layer parameters. In the second step, layer parameters obtained from the first step were used as an initial model in the computer programme "AIMRESI" (Automatic Iterative Method of Resistivity Sounding Interpretation) developed by Yadav (1995) to obtain the final model. The layer parameters obtained through the above process have been correlated with the available borehole $(\mathrm{BH})$ lithologs and modified with the help of same programme wherever possible to minimize the problems of equivalence and suppression. The parameters of several geoelectrical soundings have been correlated with the available borehole lithologs. Based on these correlations, the resistivity ranges of individual lithological unit (hydrogeology) have been identified and presented in Table 1. 


\section{International Journal of Science and Research (IJSR) \\ ISSN (Online): 2319-7064}

Index Copernicus Value (2013): 6.14 | Impact Factor (2014): 5.611

Table 1: Range of Resistivities for different Lithological Units

\begin{tabular}{|c|c|c|c|c|c|c|c|}
\hline Lithology & $\begin{array}{c}\text { Surface } \\
\text { Clay }\end{array}$ & $\begin{array}{c}\text { Clay and } \\
\text { Kankar }\end{array}$ & $\begin{array}{c}\text { Clay/ Sandy } \\
\text { Clay }\end{array}$ & $\begin{array}{c}\text { Fine to } \\
\text { Med. Sand }\end{array}$ & $\begin{array}{c}\text { Coarse } \\
\text { Sand }\end{array}$ & $\begin{array}{c}\text { Coarse Sand } \\
\text { with Morum }\end{array}$ & $\begin{array}{c}\text { Vindhyan } \\
\text { Sandstone }\end{array}$ \\
\hline Resistivity (Ohm-m) & $5-121$ & $20-85$ & $5-17$ & $20-40$ & $40-60$ & $60-150$ & $>150$ \\
\hline
\end{tabular}

\section{Results and Discussion}

\section{Vertical Geoelectrical cross-section}

Based on the geoelectrical parameters obtained through the interpretation of GS data and lithological informations obtained through boreholes, five vertical geoelectrical crosssections (marked on the location map, Fig. 1) have been prepared. As the bedrock could not be mapped due to nonavailability of space, the depth of the bedrock was estimated computing total conductance at that location. The bedrock topography mapped along each geoelectrical cross-section has been shown by continuous line whereas estimated bedrock topography has been shown by dash line.

\section{a) Vertical Geoelectrical cross-section $\mathbf{A}-\mathbf{A}^{\prime}$}

The first northern most geoelectrical cross-section oriented in the west to east direction, as shown in Fig. (2), incorporates the interpreted results of seven GS, i.e. GS-80, GS-20, GS-21, GS-61, GS-8, GS-9, GS-11 and GS-67 alongwith available lithological information from three boreholes, i.e., $\mathrm{BH}-2, \mathrm{BH}-8$ and $\mathrm{BH}-6$. The length of this geoelectrical cross-section is about $13 \mathrm{~km}$. The cross-section exhibits multilayer stratification throughout the region. The surface layer shows resistivity variation probably due to variation in moisture content or different types of clay/soil. The surface layer is underlain by a layer mixed with clay and kankar. A thick layer of medium sand is present at GS80 and GS-20 whereas thickness of this layer decreases towards east direction of the profile. Below this layer, a thick aquifer zone of coarse sand and morum with resistivity variation between $48 \mathrm{ohm}-\mathrm{m}$ and $87 \mathrm{ohm}-\mathrm{m}$ is present throughout the section except below the GS-80 and GS- 20. The resistive substratum (Vindhyan sandstone) is mapped by GS-80 and GS-08 whereas depth of Vindhyan sandstone has been estimated below GS-20, GS-21, GS-61, GS-11 and GS67 . The subsurface alluvial stratigraphy clearly shows depth wise disposition of aquifer zone alongwith Vindhyan bedrock topography at different locations along the profile line. Similar type of alluvial stratification has been shown in the following sections i.e. along B-B', C-C', D-D' and E-E' profiles.

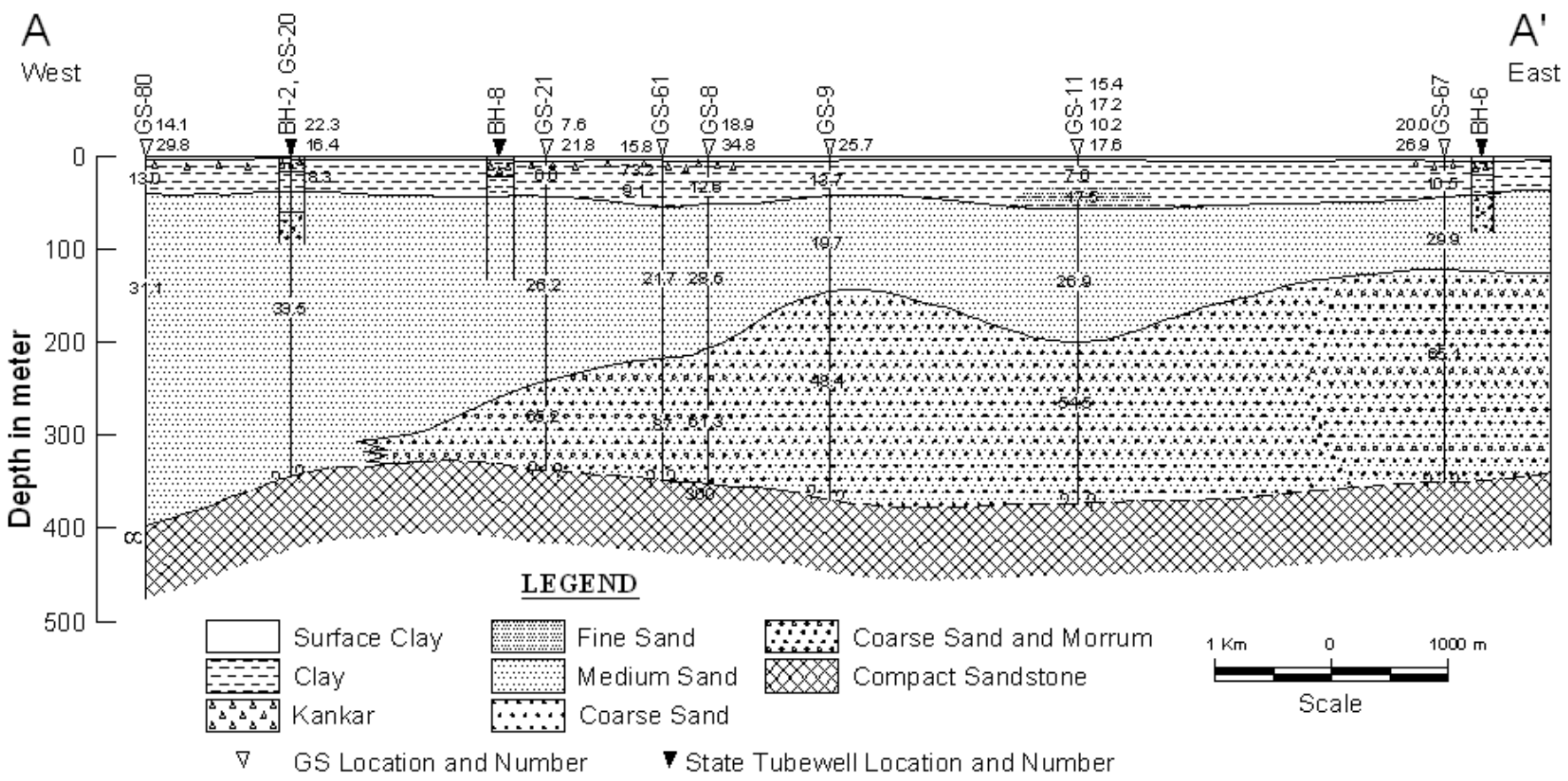

Figure 2: Geoelectrical cross section showing alluvial stratigraphy along profile A-A'.

(b) Vertical Geoelectrical cross-section B-B'

The interpreted results of twelve GS, i.e. GS-19, GS-30, GS17, GS-58, GS-16, GS-53, GS-82, GS-1, GS-13, GS-64, GS14 and GS-63 alongwith available lithological information through two boreholes, i.e., $\mathrm{BH}-14$ and $\mathrm{BH}-12$ have been utilized to prepare this section as shown in Figure (3). The length of this geoelectrical cross-section is also same as taken along section A-A'. Like previous section, surface layer resistivity varies at various GS locations because of the same reason. A thick layer of clay and/ or clay mixed with kankar is present all along the section except at GS-13, GS64 and GS-14 where thickness of clay and/or clay mixed with kankar is comparatively less. Below GS-1, GS-13, GS64 and GS-14, a layer having resistivity varying $13.2 \mathrm{ohm}-\mathrm{m}$ to $18.6 \mathrm{ohm}-\mathrm{m}$ consisting of fine sand is found. At the GS locations GS-30, GS-17, GS-13, GS-64, GS-14 and GS-63, the layer having resistivity varying from $42 \mathrm{ohm}-\mathrm{m}$ to 125.9 ohm-m is due to presence of coarse sand to morum. A thick aquifer zone having resistivity variation from $21.1 \mathrm{ohm}-\mathrm{m}$ to $125.9 \mathrm{ohm}-\mathrm{m}$ is present throughout the section. The depth of the Vindhyan sandstone is mapped by geoelectrical soundings at GS-58, GS-16, GS-53 and GS-82 and drawn by continuous line whereas the estimated depth of Vindhyan 


\section{International Journal of Science and Research (IJSR) \\ ISSN (Online): 2319-7064}

Index Copernicus Value (2013): 6.14 | Impact Factor (2014): 5.611

sandstone has been shown by dashed line below GS-19, GS-

30, GS-17, GS-1, GS-13, GS-64, GS-14 and GS-63.

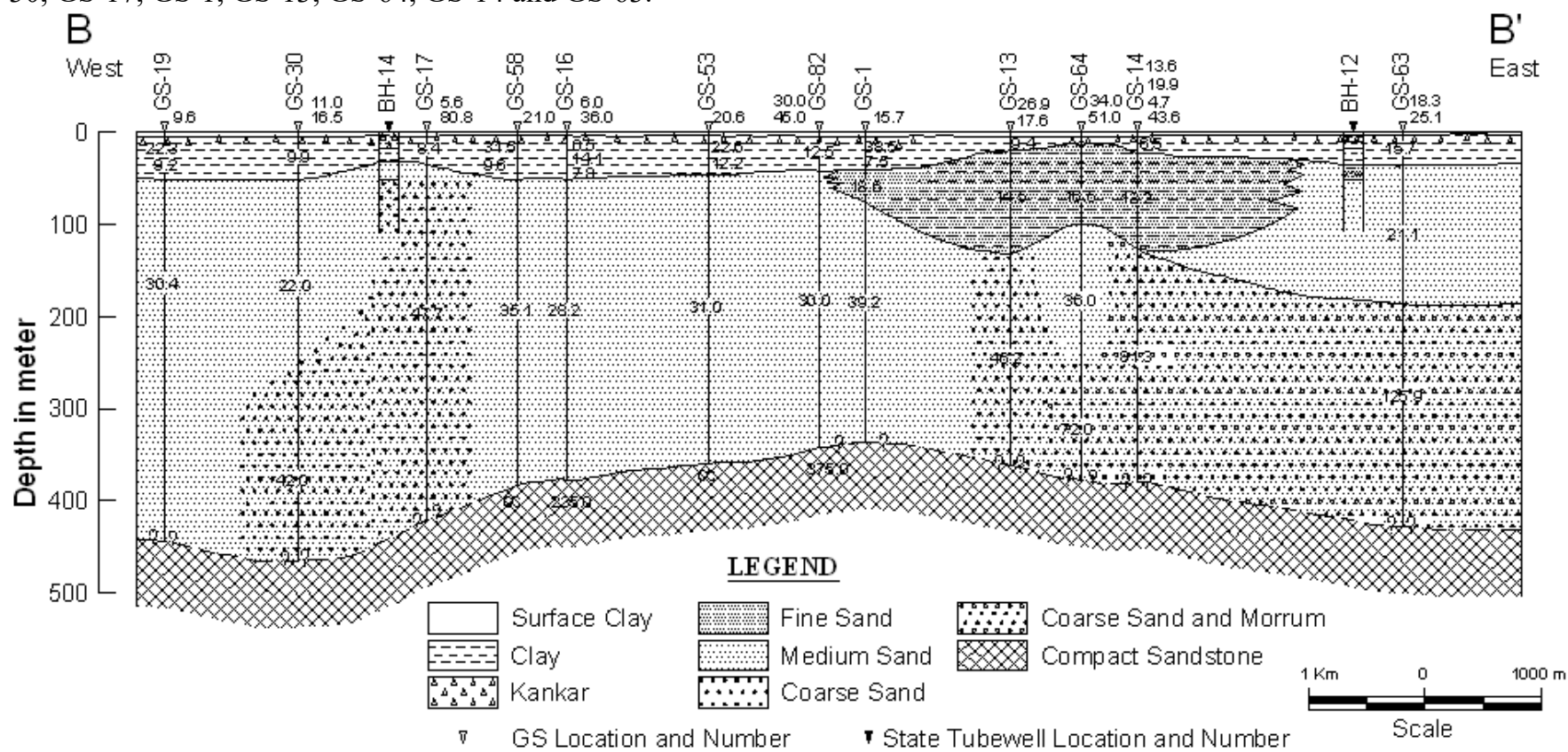

Fig. 3. Geoelectrical cross section showing alluvial stratigraphy along profile B-B'.

\section{(c) Vertical Geoelectrical cross-section C-C'}

Among all the sections extending from west to east, this section covers the southern most part of the area under study. The interpreted results of eleven geoelectrical soundings, i.e. GS-35, GS-31, GS-77, GS-72, GS-37, GS28, GS-39, GS-38, GS-84, GS-42 and GS-57 alongwith available lithological information through three boreholes, i.e., $\mathrm{BH}-18, \mathrm{BH}-20$ and $\mathrm{BH}-21$ have been used to prepare this section as shown in Fig. (4). The length of this geoelectrical cross-section is almost same as in the section
A-A'. A clay/ or clay mixed with kankar layer of varying thickness (minimum below GS-57 and maximum below GS35 and GS-31) is present all along the section directly below the surface layer. A thick layer of medium sand is present along the entire section having resistivity variation from 21 ohm-m to 37.4 ohm-m except at GS-37, GS-39 and GS-57 where coarse sand to morum is expected due to high resistivity values. Compact sandstone has been mapped all along the section except below soundings GS-35, GS-37, GS-28 and GS-39 where its depth is approximated.

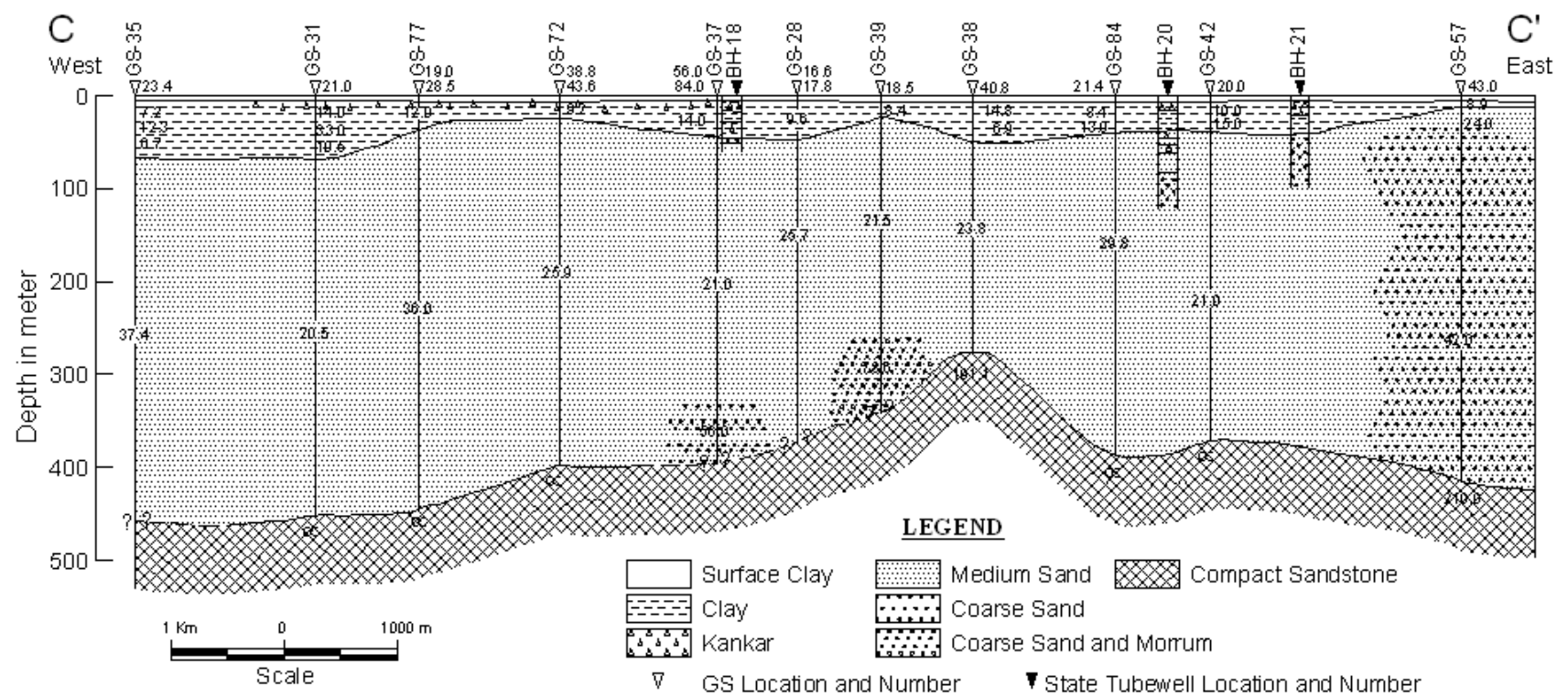

Fig. 4. Geoelectrical cross section showing alluvial stratigraphy along profile $\mathrm{C}-\mathrm{C}^{\prime}$.

\section{(d) Vertical Geoelectrical cross-section D-D'}

This section is prepared perpendicular to the earlier crosssections i.e. north to south direction. The interpreted results of eight GS, i.e. GS-81, GS-80, GS-18, GS-19, GS-32, GS35, GS-78 and GS-52 alongwith available lithological information through two boreholes, i.e., $\mathrm{BH}-1$ and $\mathrm{BH}-16$ have been taken to prepare this section as shown in Fig. (5). The length of this geoelectrical cross-section is about $12 \mathrm{~km}$. This cross-section also exhibits multilayer stratification throughout the covered region. The variation in surface layer 


\section{International Journal of Science and Research (IJSR) \\ ISSN (Online): 2319-7064 \\ Index Copernicus Value (2013): 6.14 | Impact Factor (2014): 5.611}

resistivity is found probably due to change in soil types and moisture content as observed in the previous sections. A thick layer of clay lies below the surface layer with varying thickness (minimum at GS-32 and maximum at GS-35). This layer is followed by a thick sandy zone of different grades present all along the section. The resistivity of this aquifer zone ranges from $22.8 \mathrm{ohm}-\mathrm{m}$ to $111 \mathrm{ohm}-\mathrm{m}$. The resistivity value observed below the GS-81, GS-32 and GS78 locations shows the presence of coarse sand and morum in the last layer. Compact sandstone is mapped at GS-80 and GS-52 which indicates the presence of compact Vindhyan sandstone whereas at other GS locations, the depth of compact Vindhyan sandstone is estimated.

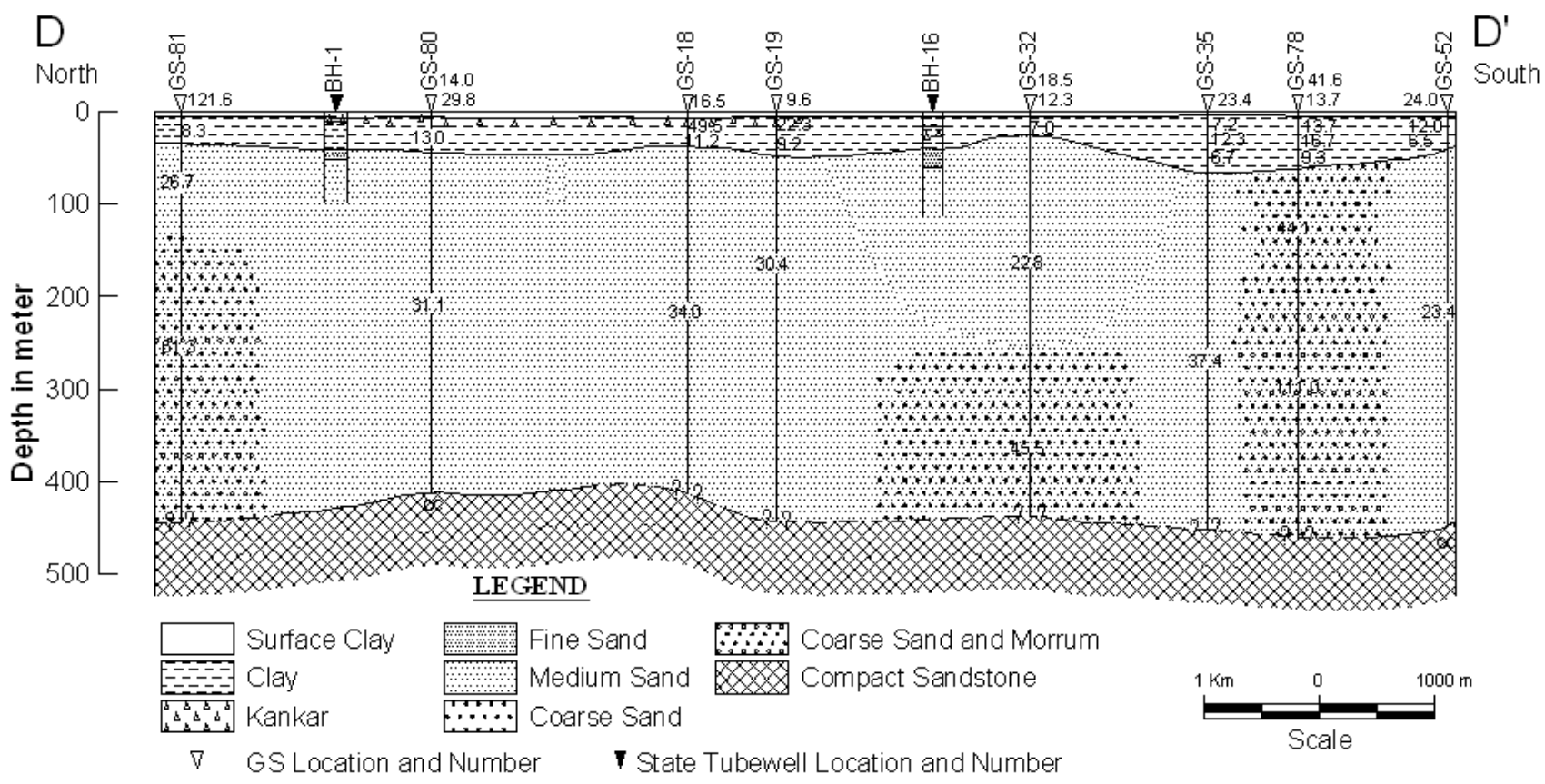

Figure 5: Geoelectrical cross section showing alluvial stratigraphy along profile D-D'.

(e) Vertical Geoelectrical cross-section E-E'

This section is also prepared parallel to the earlier crosssection F-F' based on the interpreted results of eight GS (i.e., GS-11, GS-12, GS-3, GS-64, GS-14, GS-46, GS-84 and GS-48) alongwith available lithological information through four boreholes (i.e., BH-4, BH-10, BH-20 and BH22) as shown in Fig. (6). A layer comprising clay / clay mixed with kankar is present just below the surface clay layer. This layer is followed by sandy layer having resistivity variation from $13.2 \mathrm{ohm}-\mathrm{m}$ to $99 \mathrm{ohm}-\mathrm{m}$. A patch consisting of fine sand is present at GS-11, GS-64 and GS14. Below the GS locations GS-11, GS-12, GS-64, GS-14 and GS-48, a layer of coarse to coarse sand mixed with morum has been identified. The thickness of aquifer zone is nearly uniform except below sounding GS-46 where thickness of aquifer zone is comparatively less. Depth of the Vindhyan sandstone is approximated all along the section except sounding locations at GS-46 and GS-84 where it is mapped by the array.

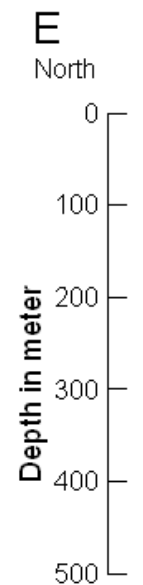

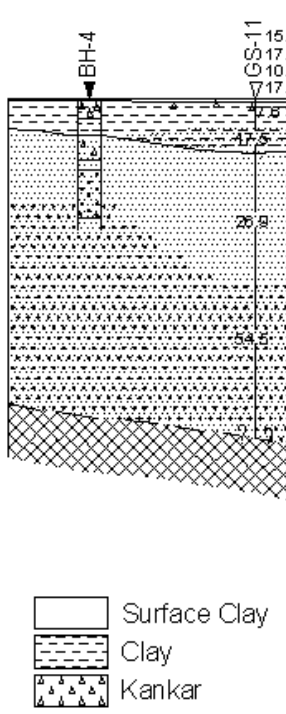

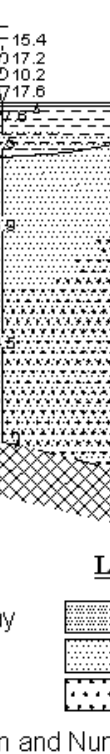

LEGEND
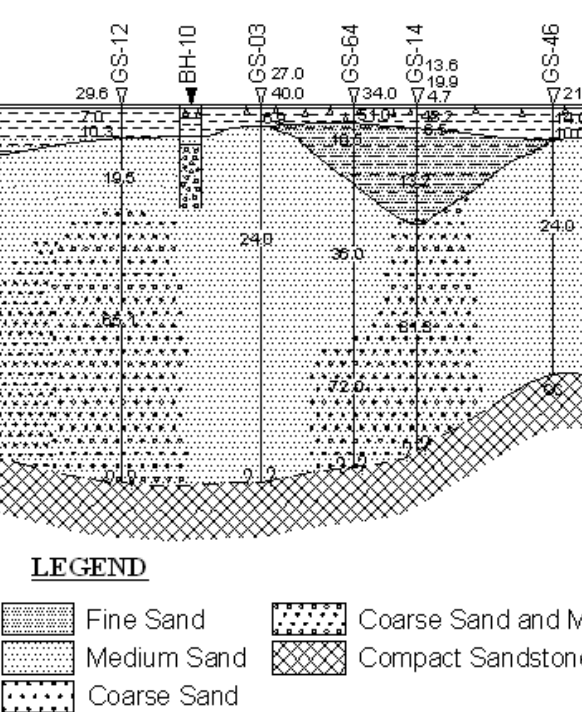

$\because \because \because \%$ Coarse Sand and Morrum Compact Sandstone

$\because \because \because$ Coarse Sand

State Tubewell Location and Number
$E^{\prime}$ South

Figure 6: Geoelectrical cross section showing alluvial stratigraphy along profile E-E'.

Volume 5 Issue 1, January 2016 


\section{International Journal of Science and Research (IJSR) \\ ISSN (Online): 2319-7064 \\ Index Copernicus Value (2013): 6.14 | Impact Factor (2014): 5.611}

\section{Horizontal Geoelectrical Cross-Sections}

The vertical geoelectrical cross-sections represent the subsurface lithology only along a line based on the results of geoelectrical soundings and borehole information. The overall variation in lithology at different depth levels throughout the region under investigation can be visualized from the horizontal cross-sections. Based on the geoelectrical parameters obtained through the interpretation of sounding data and lithological informations available through boreholes, seven horizontal geoelectrical crosssections in slice form at selected depth levels of 5, 25, 70, $100,200,300$ and $400 \mathrm{~m}$ have been prepared and presented in the form of depth wise lithological changes at different depth levels as shown in Fig. (7). It also gives a clue for the possibility of recharge and movement of ground water through surface water bodies as well as artificial recharge through other means such as roof top rainwater harvesting, injection well, pits and ponds. The description of individual cross sections is given below.

A horizontal cross-section at $5 \mathrm{~m}$ depth level reveals more or less similar characteristics as observed at the ground level with a few exceptions due to presence of few isolated patches of saturated clay. The horizontal cross-section at 25 $\mathrm{m}$ depth level reveals the presence of same saturated clay throughout the area except at few locations where fine to medium sand is present. These isolated patches of fine to medium sand form aquifers of moderate nature. The lithology at $70 \mathrm{~m}$ depth level reflects the presence of saturated sands of different grades throughout the area except few isolated patches of clay formations. These isolated patches of clay formation may not be suitable for extraction of ground water at that particular location. The horizontal cross-section at $100 \mathrm{~m}$ depth level reveals the presence of saturated fine to medium sands throughout the area except one location where an isolated patch of clay is present. There are few isolated patches of coarse grained sand to morum which may be highly productive zones for ground water at this depth level. Another horizontal crosssection at $200 \mathrm{~m}$ depth level reveals the presence of saturated sands of different grades throughout the area. The areal extent of isolated patches of coarse sand and coarse sand mixed with morum increases towards north-east direction and south-west direction which may be highly productive zone for ground water at this depth level. Similar horizontal cross-section at $300 \mathrm{~m}$ depth level shows the presence of saturated sands of different grades throughout the area. The areal extent of isolated patches of coarse grained sand to morum increases towards north and northeast directions which may be highly prolific zone for ground water. At this depth level, few isolated patches of compact Vindhyan sandstones are also present at few locations. Lastly, the horizontal cross-section at $400 \mathrm{~m}$ depth level reveals the presence of saturated sands of different grades throughout the area. The area wise extent of isolated patches of coarse grained sand to morum is decreased which may be highly productive zone for ground water at this depth level. The isolated patches of compact Vindhyan sandstone observed in the earlier section increases in dimensions and cover almost half portion of the area at this depth level.

\section{Isopach Map of Aquifer and Depth Map of Resistive Substratum (Bedrock)}

The thickness of saturated sand with different grades plays role in forming aquifer zone. It is evident from the isopach map that the thickness of the aquifer varies from 225 to 440 $\mathrm{m}$ as shown in Fig. (8). From the critical study of the map, it can be seen that the region surrounded by contour value of $360 \mathrm{~m}$ indicates the decreasing trend of aquifer thickness and runs in SE-NW direction and also in E-W direction in northern region. The maximum aquifer thickness is observed in SW direction. With the help of this map, the future development of ground water resources can be done on planned basis. The possibility of interrelated thin clay beds can not be ruled out, because indication of such beds is missed in geoelectrical soundings due to detectability problem arising due to lack of resolution of the DC resistivity method. The figure clearly depicts that water bearing formations are interconnected throughout the area under investigation which can be recharged successfully. 
International Journal of Science and Research (IJSR)

ISSN (Online): 2319-7064

Index Copernicus Value (2013): 6.14 | Impact Factor (2014): 5.611

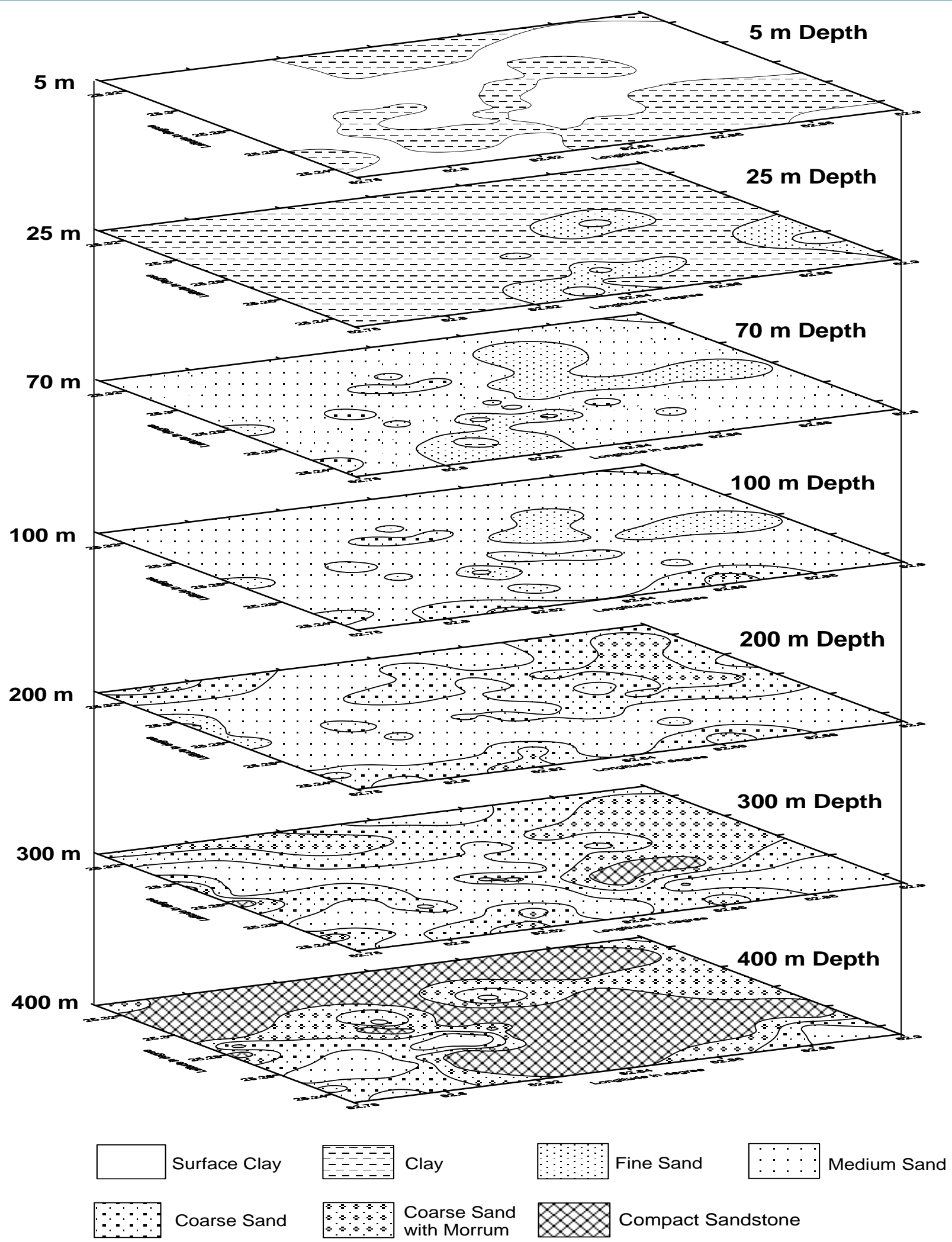

Figure 7: Horizontal geoelectrical cross-section showing the variation in lithological units at different depth levels from $5 \mathrm{~m}$ to $400 \mathrm{~m}$ depths.

Volume 5 Issue 1, January 2016 www.ijsr.net 


\section{International Journal of Science and Research (IJSR) \\ ISSN (Online): 2319-7064}

Index Copernicus Value (2013): 6.14 | Impact Factor (2014): 5.611

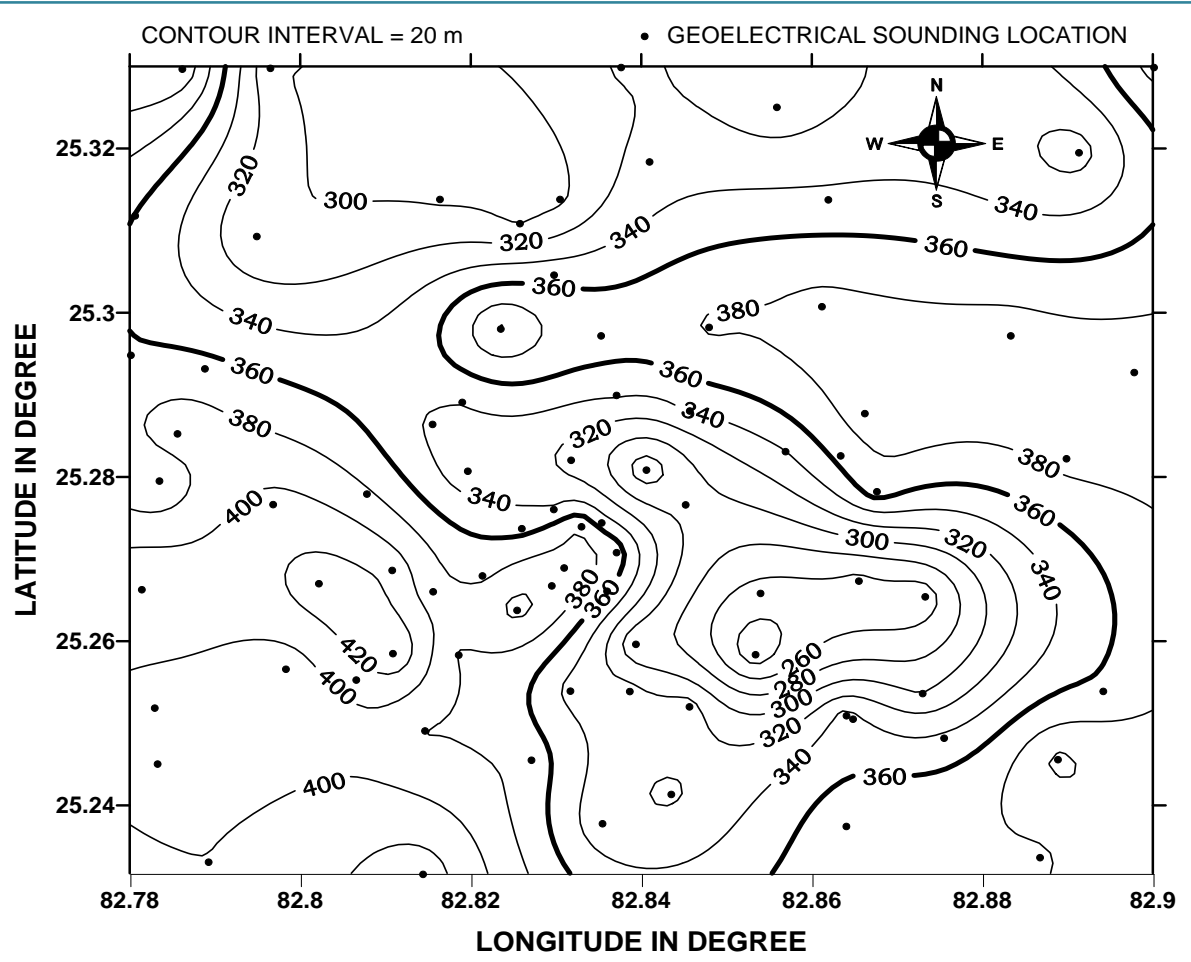

Figure 8: Isopach map of aquifer thickness.

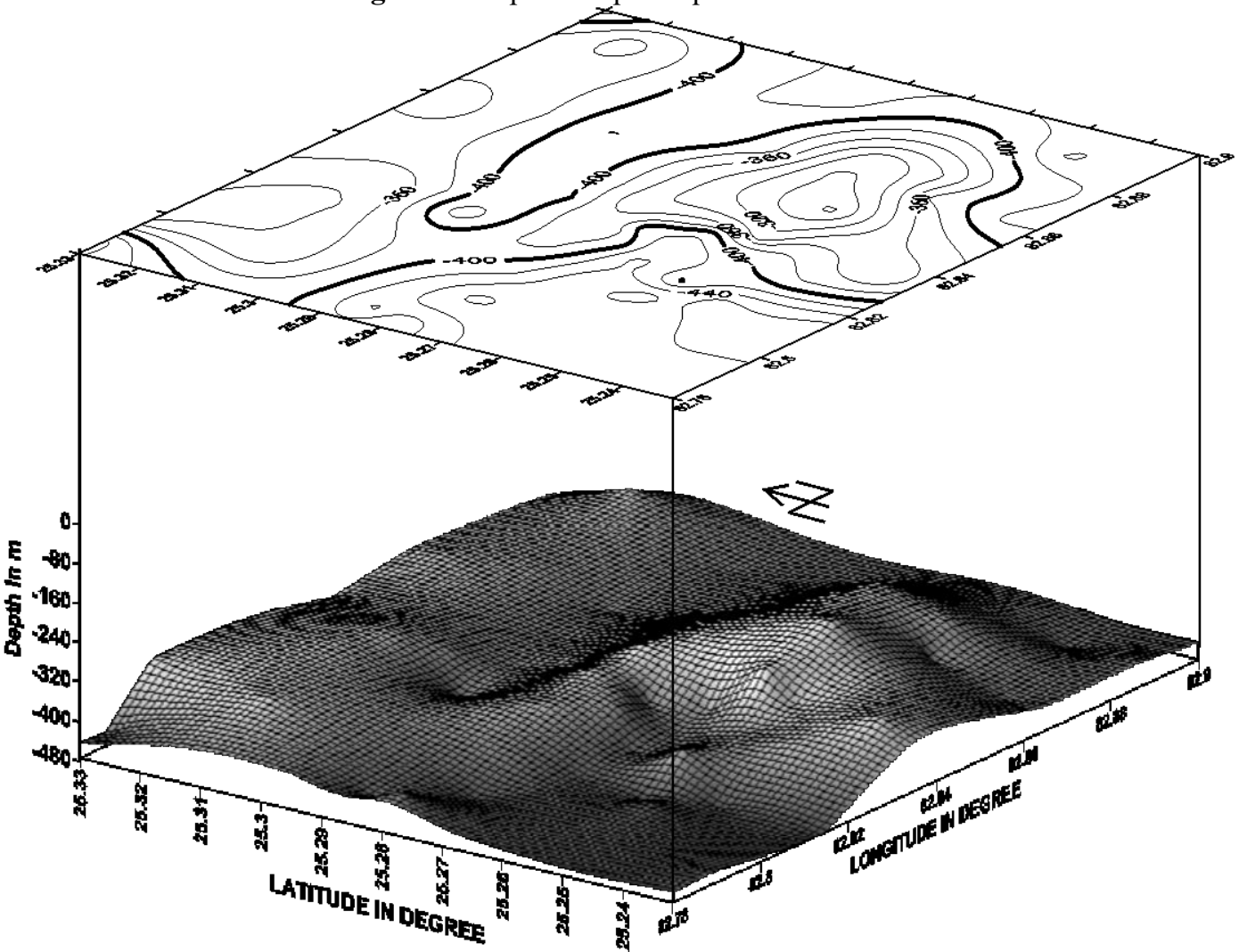

Figure 9: 3-D view showing the topography of Vindhyan Sandstone along with the depth contour below the ground surface

The depth to the resistive substratum (Vindhyan Sandstone) or the total thickness of surface soil, younger and older alluvium material overlying the bed rock, has been obtained from the geoelectrical soundings interpretation which shows the variation from 275 to $470 \mathrm{~m}$. At few locations, even with maximum current electrode separation of $1200 \mathrm{~m}$ of geoelectrical soundings, the bedrock could not be mapped for which the depth is estimated to $473 \mathrm{~m}$. On the basis of these results, contour map and 3-D view of its depth variation has been prepared and presented in Fig. (9). It is clear from the figure that the thickness of the alluvium in the south-west corner is highest. Although, the over all topography of the bedrock is undulating but the two ridges of bedrock in the area i.e., in NW-SE and E-W direction have controlled the deposition of sediments and flow of river channel. 


\section{International Journal of Science and Research (IJSR) \\ ISSN (Online): 2319-7064}

Index Copernicus Value (2013): 6.14 | Impact Factor (2014): 5.611

\section{Conclusions}

From the above study of subsurface alluvial stratigraphy, the following conclusions have been drawn. The thickness of clay layer including surface clay overlying first sandy zone is varying from place to place. The minimum thickness of clay is about $10-15 \mathrm{~m}$ and its average thickness is found to be in the range of $25 \mathrm{~m}$ which is appropriate for artificial recharge of ground water. At some places its thickness is found to be 70 - $90 \mathrm{~m}$ where borehole may be drilled exclusively for artificial recharge of aquifer zone with proper safety to avoid pollution. Medium to coarse sand, coarse sand and coarse sand mixed with morum are observed at varying depth with varying thicknesses from place to place. The resistivity value of coarse sand and coarse sand mixed with morum varies between 40 ohm-m and $125 \mathrm{ohm}-\mathrm{m}$ in the study area which can be used as a good reservoir. Isopach map of aquifer clearly shows the variation of aquifer thickness. The sandy zone having sufficient thickness (ranging from 225 to $440 \mathrm{~m}$ ) with varying grades of sand grains clearly suggests the presence of good reservoir for ground water storage. It can be emphasized that rainwater harvesting through ponds, roof top and recharging well would be more appropriate.

\section{Acknowledgements}

The authors wish to thank the Head of Department of Geophysics, B.H.U, Varanasi, India for providing the infrastructure to complete this work. Financial support provided by Hindustan Coca-Cola Beverages Pvt. Ltd. is acknowledged. We are thankful to Prof. T. Lal of the Department has gone through the manuscript and given fruitful suggestions. We are also thankful to the reviewers and editor of the journal who have given critical and thoughtful suggestions, which improved the present manuscript.

\section{References}

[1] Ebert, A., 1943. Grundlagen Zur Auswerkung geoelectrischer Tiefenmessungon, Gerlands Beitrage Zur Geopysik, BZ, Vol. 10, Issue 1, pp. 1-17.

[2] Krishnan M. S. (1982). Geology of India and Burma, 6th Ed. CBS publishers and distributors, New Delhi. $536 \mathrm{pp}$.

[3] Mehrotra M. N. (1980). Varanasi- a Geological Review, Smarika, Indian Sedimentologist Organisation. $\left(3^{\text {rd }}\right.$ Conference).

[4] Pascoe E. H. (1968). A manual of geology of India and Burma, Geol. Sur. India. Vol. 2, $3^{\text {rd }}$ Ed. Govt. of India Press, Calcutta.

[5] Pathak B. D. (1977). Geology and ground water conditions of Varanasi district, U.P. Bull.. GSI series (B) No. 41.

[6] Rijkstwaterstaat, 1969. Standard graphs for resistivity prospecting, EAEG, Netherlands.

[7] Singh, S.K. (2010). Studies on evaluation of ground water resources using geoelectrical techniques in some parts of alluvial and hard rock areas of eastern Uttar Pradesh, India. Ph.D. thesis, Banaras Hindu University, India.
[8] Wadia D. N. (1975). Geology of India $3^{\text {rd }}$ Edition. Londan Macmillan \& Co. Ltd., New York. St. Martin Press.

[9] Yadav, G.S. (1995). A FORTRAN computer program for the automatic interactive method of resistivity sounding interpretation. Acta Geodaetica et Geophysica Hungarica 30 (2-4), 363-377.

[10] Yadav, G.S. (2005). Analysis of remote sensing imagery for the study of soil types, wells, land use, cropping pattern in the area around Coca-Cola plant Mehndiganj, Rajatalab, Varanasi, U.P. Project Report submitted to Hindustan Coca-Cola Beverages Pvt. Ltd., 107 pp.

[11] Yadav, G.S. (2008). Some studies on Ground Water potential in the area around Coca-Cola plant Mehndiganj, Rajatalab, Varanasi, U.P. Project Report submitted to Hindustan Coca-Cola Beverages Pvt. Ltd., 123 pp. 